\title{
The effects of inulin combined with galacto-oligosaccharide on the various properties of synbiotic soy cheese containing Lactobacillus acidophilus KLDS 1.0738
}

\author{
X. Zhang, Y. Li, J.J. Yang, X.Y. Ma, X.D. Jia, A.L. Li, P. Du \\ Key Laboratory of Dairy Science, Ministry of Education, Food College, Northeast Agriculture University, Harbin, China
}

Corresponding Author: A.L. Li, ailimail@neau.edu.cn; P. Du, dupeng@neau.edu.cn

Received: 10 April 2020 / Accepted: 10 June 2020 / Published: 15 July 2020

(c) 2020 Codon Publications

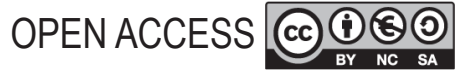

RESEARCH ARTICLE

\begin{abstract}
This study aimed to evaluate the compatibility of L. acidophilus KLDS 1.0738 (LA-1.0738) with different prebiotic carbohydrates to develop a synbiotic soft soy cheese. It was observed that the addition of $4 \%(\mathrm{~m} / \mathrm{v})$ prebiotics mixture (galacto-oligosaccharide:inulin $=1: 3$ ) to soy cheese significantly improved the growth of $L A-1.0738$, making it no less than 8.2 log colony-forming unit (CFU)/g during the 28-day storage period, but had limited influence on the viability of $S$. thermophilus KLDS T1C2 (STT1C2). Meanwhile, because of the presence of prebiotics, soy cheese fermented by $L A-1.0738$ in co-culture with STT1C2 exhibited higher values of acidity, proteolysis and lipolysis index as well as better texture properties and sensory acceptance. These results suggested that the selected combination of prebiotics could be used as functional ingredients to manufacture soy cheese to maintain the survival of desired $L A-1.0738$, which contributed to improve the texture and sensory features of soy cheese.
\end{abstract}

Keywords: L. acidophilus KLDS 1.0738, prebiotic, synbiotic, soy cheese

\section{Introduction}

With people's emphasis on diet and health, consumers' demand for nutritious and functional food is growing. Probiotics are living microorganisms which can effectively enhance human health when taken in adequate dose, including removing constipation, alleviating diarrhoea, lowering cholesterol and promoting immunity (Hana et al., 2016; Plaza-Diaz et al., 2014). Fermented dairy products containing probiotics are already one of the most popular commercial functional foods such as milk beverage, yogurt and cheese (Cassani et al., 2020). Among these, cheese is considered a better carrier of probiotics. Owing to its more dense texture and relatively higher fat content, it provides a suitable protective effect for the survival of probiotics in the gastrointestinal environment (Ong et al., 2005). The soymilk, rich in plant protein, phospholipids and isoflavones, is one of the important sources of high-quality nutrients for people in oriental countries (Chen et al., 2012) and is often called green cow's milk. There have been increasing interests in the use of probiotic-added soymilk to develop soy cheese, which also known as a tofu derivatives (Chaturika and Hyun-Dong, 2018). For example, the soy cream cheese prepared with $L$. acidophilus FTCC 0291 has been reported to contain angiotensin converting enzyme (ACE) inhibitory bioactive peptide, which is responsible for reducing high blood pressure (Liong et al., 2010). The soy-cheese spread prepared with L. casei NCDC-0017 exhibited higher antioxidant activity than the cheese sauce (Kumar et al., 2018). Therefore, the application of probiotics in soybean products can not only enhance the nutritional value of soy-based products but also expand the variety of non-dairy functional food.

The viability of probiotics during fermentation and storage determines the health effects of fermented products. Most previous research has focused on combining prebiotic ingredients to maintain or even improve the viability of probiotic strains in dairy products (Langa et al., 2019; Sebnem et al., 2019). Currently, Santos et al. (2019) indicated that adding inulin (IN) to fermented soymilk could 
not only efficiently promote the survival of Lactococcus, Lactobacillus and yeast in kefir grains but also improve the sensory acceptability of beverage during the 14-day shelf life. Furthermore, in vitro and in vivo experiments have suggested that synbiotic products generally tend to have better probiotic effects than either probiotics or prebiotics alone (Le et al., 2019; Samadrita et al., 2019). Nowadays, synbiotic soybean products have been studied almost exclusively in the fermented soy milk or soy yoghurt. However, a few studies have done research on symbiotic soybean cheese.

In our previous study, we screened a strain of L. acidophilus 1.0738 with probiotic characteristics, which had a strong tolerance to acid and bile salt and had a relief effect on intestinal inflammation in animal experiments ( $\mathrm{Li}$ et al., 2017a). In the present study, we adopted $L$. acidophilus strain and different prebiotic oligosaccharides to develop a potentially synbiotic soft soybean cheese. The protective effect of different prebiotics on the survival of L. acidophilus in soy cheese was explored. Moreover, the changes in physicochemical and microbiological, and texture and sensory properties of probiotic soybean cheese were analysed during storage.

\section{Materials and methods}

\section{Probiotic strains and prebiotics}

L. acidophilus KLDS 1.0738 (LA-1.0738) and S. thermophilus KLDS T1C2 (STT1C2) obtained from Key Laboratory of Dairy Science, Ministry of Education (Northeast Agricultural University, Harbin, China) were cultured in DeMan-Rogosa-Sharpe (MRS) agar (Sigma, US) and M17 broth (Huankai Microbial, China) at $37^{\circ} \mathrm{C}$ for $24 \mathrm{~h}$, respectively. After three consecutive transfers, the inoculum concentration of L. acidophilus and S. thermophilus starter was adjusted to $9 \mathrm{log} \mathrm{CFU} / \mathrm{g}$ for making soy cheese.

Commercial prebiotics were added to soy cheese: fructo-oligosaccharides (FOS) and oligoisomaltose (IMO) were purchased from RYON Co. Ltd. (Shanghai, China), galacto-oligosaccharides (GOS) was purchased from BIOTOPPED Co. Ltd. (Beijing, China), and mannan-oligosaccharides (MOS) and IN were purchased from Shanghai Yuanye Bio-Technology Co. Ltd. (Shanghai, Chain).

\section{Selection of suitable probiotics}

The experiment in this section is divided into three parts. Firstly, we used MRS $^{- \text {dex }}$ (MRS without glucose) to analyse the effects of different prebiotics (FOS, IMO, GOS, MOS and IN) on the growth of $L A-1.0738$, that is, after incubating at $37^{\circ} \mathrm{C}$ for $24 \mathrm{~h}$, the optical density $\left(\mathrm{OD}_{600}\right)$ of $L A-1.0738$ in $\mathrm{MRS}^{\text {-dex }}$ containing different prebiotics was determined using a CHEMUSB4-UV-VIS spectrophotometer (Ocean Optics, Inc., US). Then we also used the $\mathrm{OD}_{600}$ value of $L A-1.0738$ as an indicator to evaluate the appropriate dosage of prebiotic (0-5\%, m/v) added to the $\mathrm{MRS}^{- \text {dex }}$. Finally, we evaluated the effects of different proportions of probiotic combinations (GOS and IN ratios of $1: 1,1: 2,1: 3,2: 1$ and $3: 1$ ) on the growth of $L A-1.0738$, including investigating the $\mathrm{OD}_{600}$ value in $\mathrm{MRS}^{-\mathrm{dex}}$ and the number of viable bacteria in soy cheese.

\section{Preparation of synbiotic soy cheese}

Soy cheese was made according to the method described by Matias et al. (2014). Briefly, soybeans (soy:water = $1: 3, w / v)$ soaked overnight were ground and sieved to obtain soy milk. After adding with $4 \%(\mathrm{~m} / \mathrm{v})$ prebiotics mixture (galacto-oligosaccharide: $\mathrm{IN}=1: 3$ ), the soy milk was sterilised in HVE-50 autoclave (Hirayama, Japan) at $0.1 \mathrm{MPa}, 121{ }^{\circ} \mathrm{C}$ for $20 \mathrm{~min}$ and cooled to $37^{\circ} \mathrm{C}$. Subsequently, 5\% (v/v) lactic acid bacteria ( $L A-1.0738: S T T 1 C$ = 1:1) was inoculated into soy milk for fermentation, followed by adding $3 \%(\mathrm{~g} / \mathrm{L}) \mathrm{CaCl}_{2}$ solution for coagulation until $\mathrm{pH} 4.8$ was obtained. Then the curd was cut into $2 \times 2 \times 2 \mathrm{~cm}$ cubes and drained completely, vacuum-packed in a sealed plastic bag and stored at $4{ }^{\circ} \mathrm{C}$ for 28 days. Three formulations of soy cheese were produced each with $L A-1.0738$ alone (P), $L A-1.0738$ and $S T$ T1C2 combination (PS) and $L A-1.0738, S T$ T1C2 and prebiotics compound (PSP).

\section{Physico-chemical analyses}

The $\mathrm{pH}$ value was measured using a digital $\mathrm{pH}$-meter (METTLER TOLEDO, Zurich, Switzerland). Total acidity and free fatty acid (FFA) content were determined according to the Association of Official Analytical Chemists (AOAC, 2000) Method Nos. 935.57 and 940.28, respectively. The $\mathrm{pH} 4.6$ soluble nitrogen ( $\mathrm{pH} 4.6 \mathrm{SN}$ ) was determined according to the method of Feeney et al. (2001).

\section{Instrumental texture profile analysis (TPA)}

Texture properties of soft soy cheese were determined at room temperature $\left(25{ }^{\circ} \mathrm{C}\right)$, using a texture analyser (TA-XT2i, Stable Micro Systems, Surrey, UK). The metallic cylinder probe was $\mathrm{P} / 0.5 \mathrm{~S}$ (20 $\mathrm{mm}$ in diameter), the compression distance was $10 \mathrm{~mm}$, the contact force was $0.2 \mathrm{~N}$, the pre-test and test speed was $1.0 \mathrm{~mm} \mathrm{~s}^{-1}$, and the post-test speed was $10 \mathrm{~mm} \mathrm{~s}^{-1}$. Parameters consisted of hardness, springiness, cohesiveness, gumminess and resilience. The value of texture was the mean value of quintuplicates. 


\section{Microbiological analysis}

Changes of viable $L A-1.0738$ and STT1C2 numbers in soy cheese were monitored weekly during storage period (1 up to 28 days). For this purpose, $25 \mathrm{~g}$ of duplicate soy cheese sample was diluted with $225 \mathrm{ml}$ of $0.1 \%(\mathrm{~g} / \mathrm{ml})$ peptone water in Bag Mixer 400 (Interscience, St. Nom, France) and submitted to serial dilutions with the same diluent. LA-1.0738 was counted by pour-plating $1 \mathrm{ml}$ of each dilution in modified MRS agar containing maltose (BioFroxx, Germany), after $48 \mathrm{~h}$ of aerobic incubation at $37{ }^{\circ} \mathrm{C}$. STT1C2 was counted by pour-plating $1 \mathrm{ml}$ of each dilution in M17 agar (Huankai Microbial, China) with added lactose (Oxoid, Britain), followed by incubation at $37^{\circ} \mathrm{C}$ for $48 \mathrm{~h}$.

\section{Sensory analysis}

The sensory properties of the final product were evaluated at $25^{\circ} \mathrm{C}$ by 15 trained judges (seven males and eight females), who were students, aged 20-30 years, at Northeast Agricultural University, China. The samples (P, PS and PSP) were placed in separate plastic pots, encoded with three random digits, and provided to trained panelists. According to the method described by Hough (2010), 15 trained panelists were invited to rate the sensory attributes of soy cheese for texture, mouth feel, appearance, taste and overall acceptability using a 9-point intensity scale, with 1 being the lowest score and 9 the highest. Results were given as the average of three trials for each of the samples, which formed a radial graph.

\section{Compositional analysis of final products}

The composition of final products was estimated using official methods (AOAC, 2000): moisture (Method No. 968.11), proteins (Method No. 99120), ash (Method No. 94546) and fat (Method No. 989.05). The yield of soybean cheese was calculated with the following equation:

$\%$ Yield $=\frac{\text { Weight }(\mathrm{g}) \text { final product }}{\text { Weight }(\mathrm{g}) \text { soybean used }} \times 100$

\section{Statistical analysis}

Data analysis was carried out using SPSS Inc. software (version 22.0) (SPSS Inc., Chicago, IL, USA). One-way analysis of variance was used to study the significant difference between mean values at a significance level of $P=0.05$. Mean comparisons were carried out using Tukey's test. Principal component analysis (PCA) data was performed using the Origin 2018 for Windows statistical software package (Origin Lab Co., Northampton, MA). All experimental data were expressed as mean \pm standard deviation (SD).

\section{Results and discussion}

\section{The effect of different prebiotics on $L$. acidophilus growth}

The effectiveness of synbiotic depends on the ability of probiotics to utilise prebiotic (Ann et al., 2007), which is strain-specific and dose-dependent (Santichai et al., 2019). As shown in Figure 1a, compared with the non-prebiotic MRS $^{\text {-dex }}$ (control group), the addition of prebiotics significantly increased the $\mathrm{OD}_{600}$ of $L A-1.0738$ in $\mathrm{MRS}^{-\mathrm{dex}}$. In particular, the value of $\mathrm{OD}_{600}^{600}$ in GOS and IN groups was higher than those of other oligosaccharide groups. Many studies have confirmed that L. acidophilus could use GOS and/or IN, and the underlying mechanism was that $L$. acidophilus could activate a precursor of enzymes $\beta$-fructosidase and $\beta$-galactosidases, necessary for the utilisation of IN and GOS (Andersen et al.; Endo et al., 2012). Although the growth of $L A-1.0738$ showed the highest $\mathrm{OD}_{600}$ value when the amount of GOS and IN added reached 5\%, it was not significant compared to the $4 \%$ group (Figure $1 \mathrm{~b}$ ). In addition, when the ratio of GOS:IN is 1:3, the $\mathrm{OD}_{600}$ value of probiotics in $\mathrm{MRS}^{\text {-dex }}$ medium (Figure 1c) and the number of viable bacteria in soy cheese (Figure 1d) were significantly higher than those in other groups. Ambalam et al. (2015) also indicated that the combination of different prebiotics promoted the growth of L. paracasei F8 and L. plantarum F44 more effectively than done by single prebiotic. Accordingly, we added $4 \%$ prebiotic (GOS:IN = 1:3) in subsequent experiments to produce probiotic soy cheese.

\section{Viability of $L A-1.0738$ and $S T T 1 C 2$ during storage}

Previous studies mostly used pure culture bacteria to ferment soybean products (Liong et al., 2010; Rui et al., 2017). There are few studies on soy cheese fermented with mixed probiotics and yogurt starter. In our study, the individual $L A-1.0738$ was difficult to grow well in the soy cheese, the number of viable bacteria decreased significantly in the first 20 days, and there was almost no change between 21 and 28 days, resulting in the $L A-1.0738$ numbers dropping to $6.58 \log \mathrm{CFU} / \mathrm{g}$ in the final product. Although the population of $L A-1.0738$ in the soy cheese fermented by $L A-1.0738-S T T 1 C 2$ combination also showed a downward trend between 14 and 28 days, but the amount of LA-1.0738 always remained above $7 \log$ CFU/g (Table 1), suggesting that LA-1.0738 survived much better in the presence of $S T \mathrm{~T} 1 \mathrm{C} 2$. Consistent with the observed symbiotic results of $L A-1.0738$ and STT1C2, Matias et al. (2014) also found that $L$. acidophilus La- 5 and B. animalis Bb-12 maintained satisfactory probiotic counts ( $>6 \log \mathrm{CFU} / \mathrm{g}$ ) in soy cheese after co-cultivation with $S$. thermophile starter.

Next, we further evaluated the protective effect of prebiotcs on the survival of probiotic organisms. As shown in 

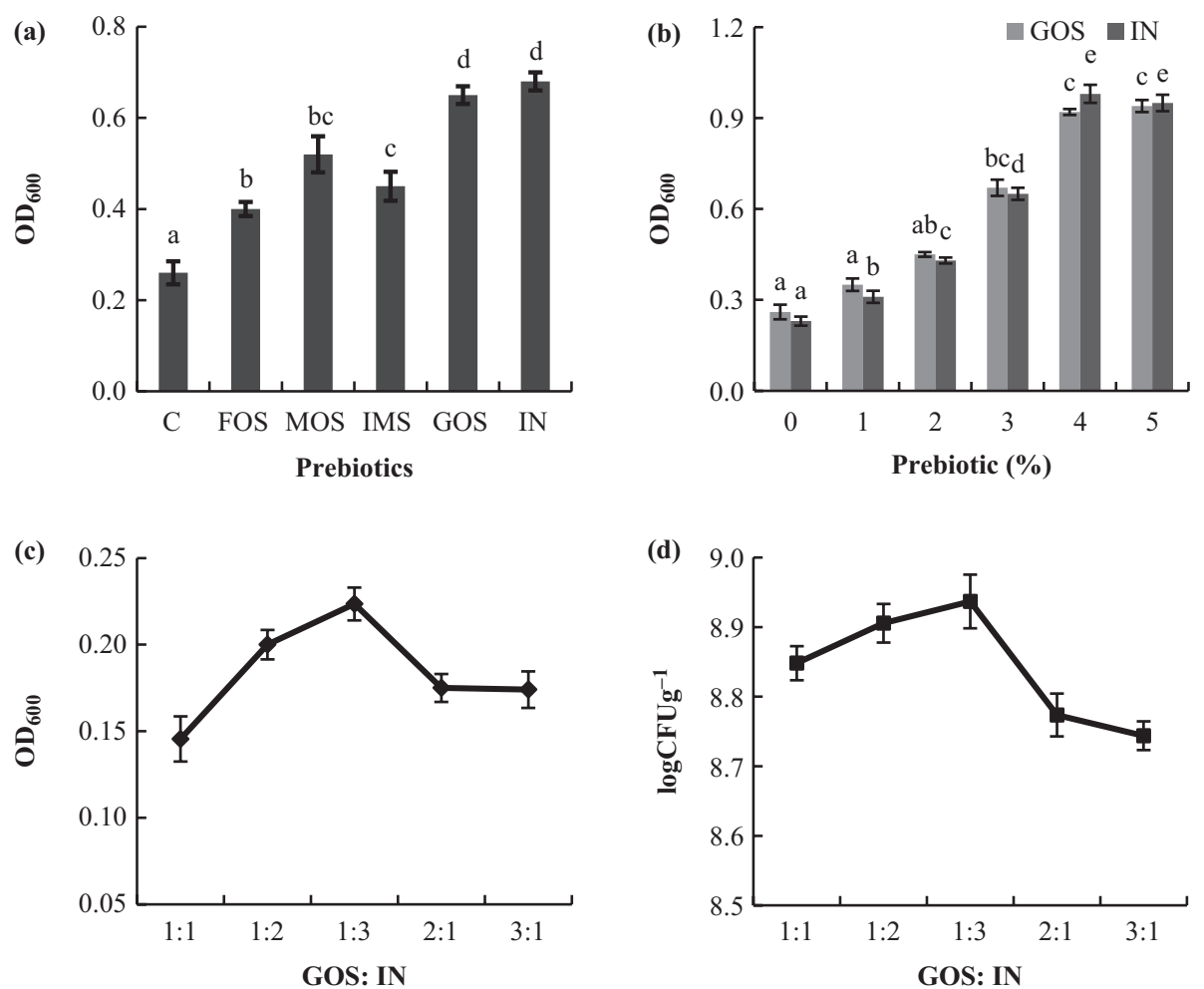

Figure 1. The effects of prebiotics on the growth of $L A-1.0738$ : (a) Changes in $\mathrm{OD}_{600}$ for $L$. acidophilus in MRS ${ }^{\text {-dex }}$ with different prebiotics; (b) changes in $\mathrm{OD}_{600}$ for $L$. acidophilus in MRS ${ }^{\text {-dex }}$ with different concentrations of prebiotics; (c) changes in $\mathrm{OD}_{600}$ for $L$. acidophilusin MRS ${ }^{\text {-dex }}$ with different IN to GOS ratios; (d) changes of viable counts of $L$. acidophilus in soy cheese with different IN to GOS ratios. Note: C, control group; FOS, fructo-oligosaccharides; MOS, mannan-oligosaccharides; IMO, oligoisomaltose; GOS, galacto-oligosaccharides; IN, inulin; MRS ${ }^{\text {-dex }}$, MRS without glucose. Different letters on top of the bars denote significant difference $(P<0.05)$. Error bars represent the mean \pm standard deviation values of triplicate experiments.

Table 1. The viable counts of $L$. acidophilus KLDS 1.0738 and S. thermophilus T1C2 in soy cheese during storage period of 28 days at $4^{\circ} \mathrm{C}$.

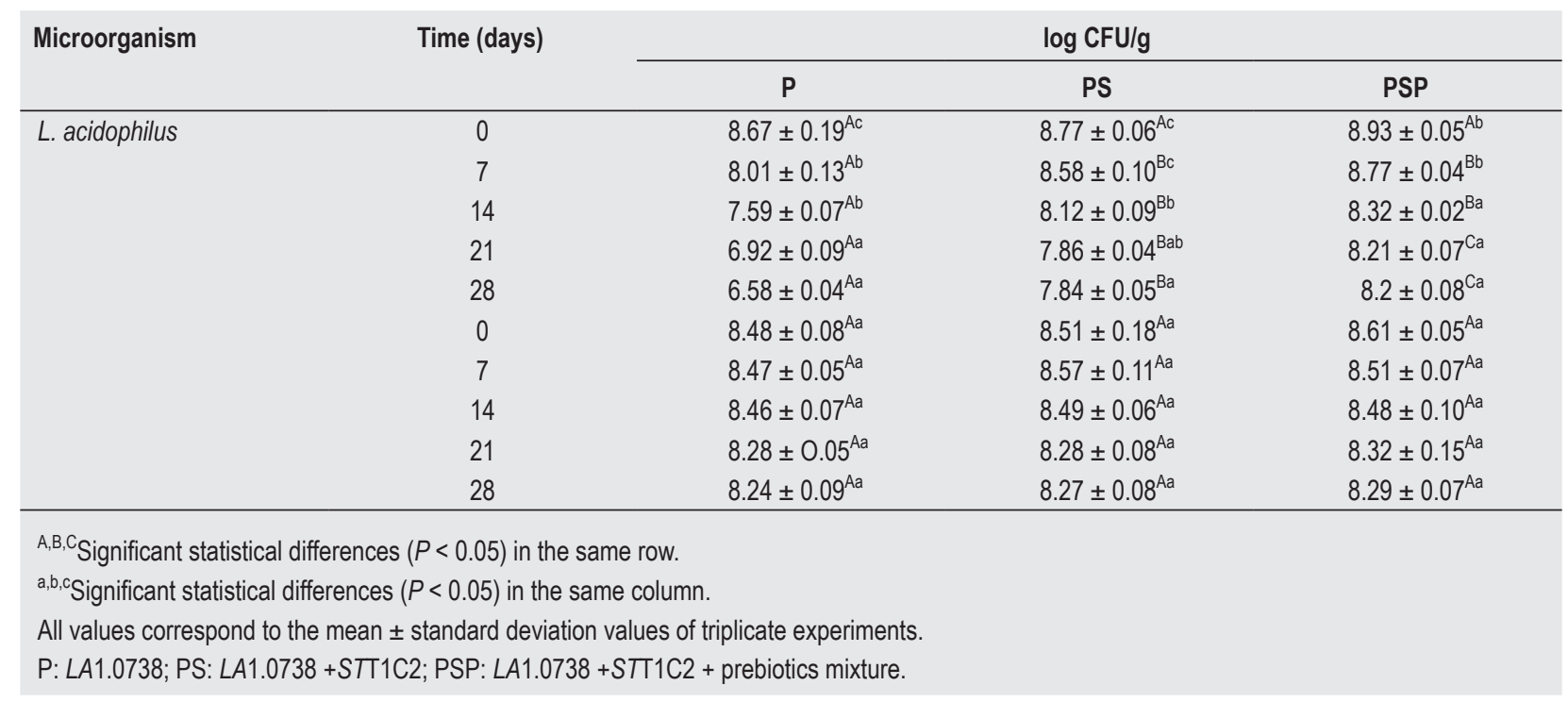


Table 2. Changes in the physicochemical characteristics of cheese samples during storage time.

\begin{tabular}{|c|c|c|c|c|c|}
\hline Cheese & Time (d) & $\mathrm{pH}$ & Total acidity (\%) & pH 4.6 SN (\%) & FFA $(\%)$ \\
\hline \multirow[t]{5}{*}{$P$} & 0 & $4.5 \pm 0.03^{\mathrm{Ab}}$ & $0.50 \pm 0.05^{\mathrm{Aa}}$ & $9.42 \pm 0.07^{\mathrm{Aa}}$ & $5.05 \pm 0.13^{\mathrm{Aa}}$ \\
\hline & 7 & $4.51 \pm 0.03^{\mathrm{Bb}}$ & $0.52 \pm 0.01^{\mathrm{Aab}}$ & $9.83 \pm 0.08^{\mathrm{Aa}}$ & $5.72 \pm 0.05^{\mathrm{Ab}}$ \\
\hline & 14 & $4.39 \pm 0.02^{\mathrm{Bab}}$ & $0.56 \pm 0.03^{\mathrm{Bab}}$ & $11.20 \pm 0.19^{A b}$ & $6.01 \pm 0.05^{\mathrm{Abc}}$ \\
\hline & 21 & $4.31 \pm 0.03^{\mathrm{Bab}}$ & $0.59 \pm 0.02^{\mathrm{Bab}}$ & $12.58 \pm 0.01^{\mathrm{Ac}}$ & $6.47 \pm 0.19^{A C}$ \\
\hline & 28 & $4.29 \pm 0.05^{\mathrm{Aa}}$ & $0.64 \pm 0.04^{\mathrm{Bb}}$ & $13.90 \pm 0.07^{\mathrm{Ac}}$ & $6.60 \pm 0.27^{\mathrm{Ac}}$ \\
\hline \multirow[t]{5}{*}{ PS } & 0 & $4.52 \pm 0.02^{A b}$ & $0.54 \pm 0.01^{\mathrm{Aa}}$ & $9.13 \pm 0.05^{\mathrm{Aa}}$ & $5.21 \pm 0.13^{\mathrm{Aa}}$ \\
\hline & 7 & $4.35 \pm 0.07^{\mathrm{ABab}}$ & $0.60 \pm 0.04^{\mathrm{Aab}}$ & $11.45 \pm 0.50^{\mathrm{Bb}}$ & $5.28 \pm 0.11^{\mathrm{Aa}}$ \\
\hline & 14 & $4.29 \pm 0.02^{\mathrm{Aa}}$ & $0.68 \pm 0.01^{\mathrm{Ab}}$ & $13.70 \pm 0.52^{\mathrm{Bbc}}$ & $6.31 \pm 0.14^{\mathrm{Ab}}$ \\
\hline & 21 & $4.31 \pm 0.03^{\mathrm{ABa}}$ & $0.69 \pm 0.02^{A b}$ & $14.90 \pm 0.15^{\mathrm{Bc}}$ & $7.20 \pm 0.07^{\mathrm{Ab}}$ \\
\hline & 28 & $4.23 \pm 0.07^{\mathrm{Aa}}$ & $0.70 \pm 0.03^{\mathrm{Ab}}$ & $15.10 \pm 1.20^{\mathrm{ABC}}$ & $7.33 \pm 0.11^{\mathrm{Ab}}$ \\
\hline \multirow[t]{5}{*}{ PSP } & 0 & $4.51 \pm 0.04^{\mathrm{Ac}}$ & $0.54 \pm 0.02^{\mathrm{Aa}}$ & $9.13 \pm 0.21^{\mathrm{Aa}}$ & $5.01 \pm 0.13^{\mathrm{Aa}}$ \\
\hline & 7 & $4.32 \pm 0.02^{\mathrm{Abc}}$ & $0.62 \pm 0.03^{\mathrm{Ab}}$ & $10.95 \pm 0.10^{\mathrm{Ba}}$ & $6.87 \pm 0.06^{\mathrm{Bb}}$ \\
\hline & 14 & $4.21 \pm 0.03^{\mathrm{Ab}}$ & $0.66 \pm 0.01^{\mathrm{Abc}}$ & $14.35 \pm 0.92^{\mathrm{Bb}}$ & $7.23 \pm 0.19^{\mathrm{Bbc}}$ \\
\hline & 21 & $4.19 \pm 0.02^{\mathrm{Ab}}$ & $0.70 \pm 0.02^{\mathrm{Ac}}$ & $15.04 \pm 1.74^{\mathrm{Bb}}$ & $7.67 \pm 0.16^{\mathrm{BC}}$ \\
\hline & 28 & $4.17 \pm 0.01^{\text {Aab }}$ & $0.73 \pm 0.02^{A c}$ & $15.81 \pm 0.09^{\mathrm{ABb}}$ & $7.81 \pm 0.24^{\mathrm{BC}}$ \\
\hline \multicolumn{6}{|c|}{${ }^{A, B, C}$ Significant statistical differences among different cheese in the same column $(P<0.05)$. } \\
\hline \multicolumn{6}{|c|}{ a,b,c Significant statistical differences among different days in the same column $(P<0.05)$. } \\
\hline \multicolumn{6}{|c|}{ All values correspond to the mean \pm standard deviation values of triplicate experiments. } \\
\hline \multicolumn{6}{|c|}{ P: LA1.0738; PS: LA1.0738 +STT1C2; PSP: LA1.0738 +STT1C2 + prebiotics mixture; FFA: free fatty acid; SN: soluble nitrogen. } \\
\hline
\end{tabular}

Table 1, compared with the $L A-1.0738$ alone group or the STT1C2 starter co-culture group, the $L A-1.0738$ counts in the GOS-IN group increased significantly during storage $(P<0.05)$, which was not less than $8.2 \log \mathrm{CFU} / \mathrm{g}$ on day 28. Similar finding was reported by Mishra and Mishra (2018), who found improvements in the growth of $L$. acidophilus in the symbiotic soy milk supplemented with IN and FOS. Unlike $L A-1.0738$, we observed that the prebiotics had little effect on STT1C2 counts, varying between 8.29 and $8.61 \log$ CFU/g (Table 1), which might be related to the lack of oligosaccharide degrading enzymes in the S. thermophilus. Our previous studies have confirmed that the minimum amount of $L A-1.0738$ to produce health effects was 6-7 log CFU/g daily product consumption (Wang et al., 2018), suggesting the potential benefits of soy cheese as probiotic vehicle.

\section{Physico-chemical analysis of soy cheese during storage}

It is evident in Table 2 that compared with the group with $L A-1.0738$ alone, the $\mathrm{pH}$ value of soy cheese containing starter or prebiotic decreased during the storage period of 1-14 days, and the titration acidity increased $(P<0.05)$. Although the $\mathrm{pH}(4.17)$ of soy cheese with prebiotics after 28 days of storage was lower than the $\mathrm{pH}$ of soy cheese with starter (4.23), there was no significant difference between the two groups $(P>0.05)$. This decrease in $\mathrm{pH}$ value was similar to the observation made by Bergamini et al. (2009). In addition, all soy cheese formulas showed strong proteolytic and lipolytic abilities during 7-21 days, reaching maximum on day 28 (Table 2). Compared with the $L A-1.0738$ alone group, the mixed fermentation group of probiotics and starter had better results, and their $\mathrm{pH} 4.6 \mathrm{SN}$ and FFA values increased by $15.10 \%$ and $7.33 \%$, respectively, at the end of storage. Consistent with our results, Li et al. (2019) reported that L. plantarum, B. animalis Bb-12 and $S$. thermophilus-mixed fermented milk had higher titratable acidity, proteolytic activity and lipolytic capacity than the pure $S$. thermophilus group. We further observed that, compared with the $L A-1.0738$ alone group and the supplemented yogurt starter group, the FFA of soy cheese with prebiotics increased significantly $(P<0.05)$ and reached the highest value in 28 days (7.81\%). Similarly, Rodrigues et al. (2012) also observed that the addition of FOS and IN (ratio 1:1) positively promoted lipolysis action and FFA production of cheese containing L. casei-01 and B. lactis B94 during storage.

\section{Textural properties of soy cheese during storage}

It is observed in Table 3 that the hardness of the three groups of soy cheese increased significantly $(P<0.05)$ during storage and reached their maximum values on the 28th day, which were $757.42,674.60$ and $624.32 \mathrm{~g}$, respectively. According to literature, it was speculated that the extracellular polysaccharides or bioactive ingredients produced by probiotics could increase viscosity, the water retention capacity, which thereby increased the hardness in the final product (Welman and Maddox, 2003). These results were supported by Li et al. (2017b), who pointed out that the addition of $L$. acidophilus to tofu could 


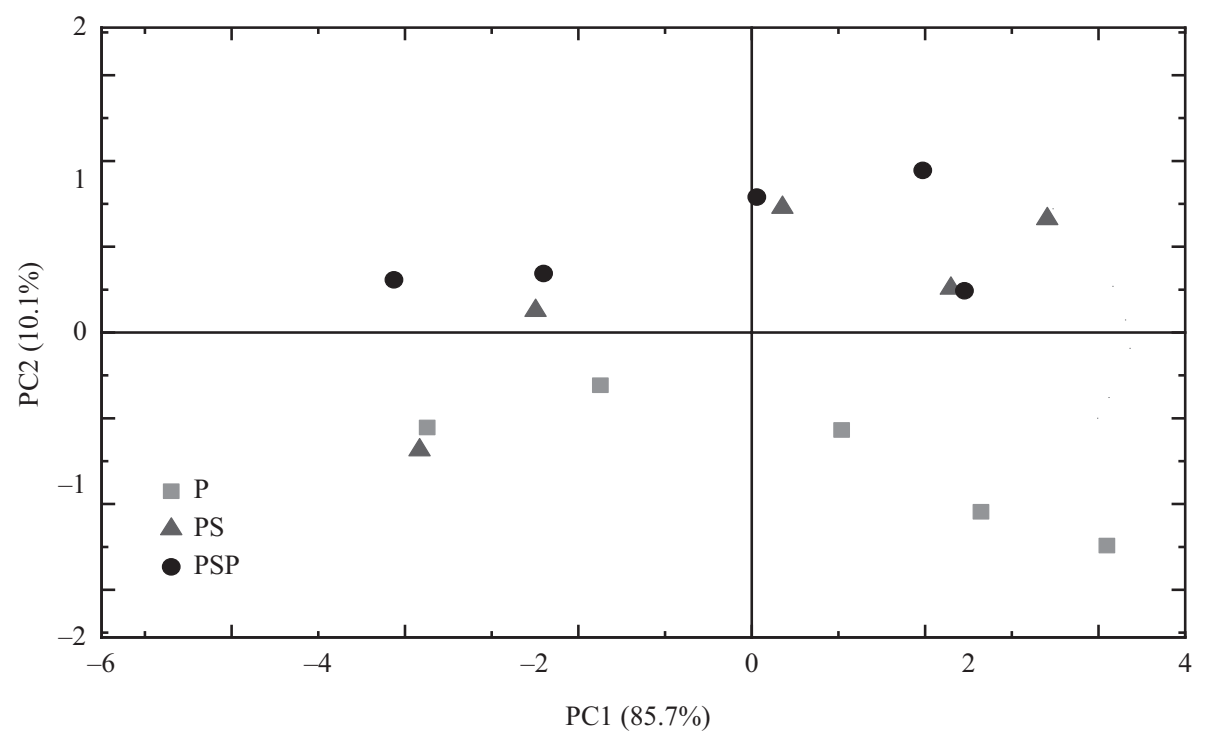

Figure 2. Principal component analysis of the textural parameters of cheese during storage. Note: P, LA-1.0738; PS, LA-1.0738 + STT1C2; PSP, LA-1.0738 + STT1C2 + prebiotics mixture.

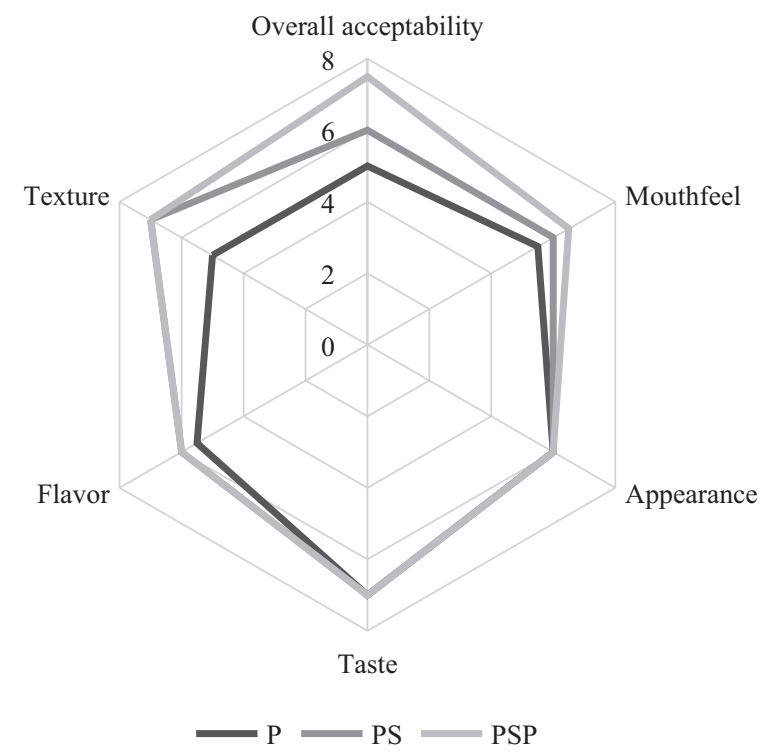

Figure 3. Sensory evaluation of cheese samples at the end of storage. Note: P, LA-1.0738; PS, LA-1.0738 + STT1C2; PSP, $L A-1.0738+S T T 1 C 2+$ prebiotics mixture. reported that the synbiotic soy beverages containing IN, L. acidophilus $\mathrm{La}-5$, B. animalis $\mathrm{Bb}-12$ and S. thermophilus were more acceptable. Cardarelli et al. (2007) also found that adding IN helped to improve the mouth feel and texture of petit-suisse cheese containing $S$. thermophilus and L. acidophilus.

\section{Gross composition of soy cheese}

As shown in Table 4, the addition of GOS and IN mixture resulted in the lowering of protein and fat content in the finished soy cheese, which might be due to the prebiotics increasing the activity of probiotics, resulting in more intense proteolysis and lipolysis (Valle et al., 2019). Although the protein and fat content of the co-culture group of STT1C2 and $L A-1.0738$ was lower than that of the probiotics alone group, the difference between the two groups was not significant. Moreover, the addition of starter or prebiotic had no significant effect on the yield (65.57 vs. 72.09 g per $100 \mathrm{~g}$ ), moisture (64.38 vs. $68.20 \mathrm{~g}$ per $100 \mathrm{~g})$ and ash ( $0.62 \mathrm{vs.} 0.66 \mathrm{~g}$ per $100 \mathrm{~g})$ of the soy cheese.

Table 4. Chemical composition of cheese samples at the end of ripening ( 28 days).

\begin{tabular}{|c|c|c|c|c|c|}
\hline Samples & $\begin{array}{c}\text { Yield } \\
(\mathrm{g} / 100 \mathrm{~g})\end{array}$ & $\begin{array}{l}\text { Moisture } \\
(\mathrm{g} / 100 \mathrm{~g})\end{array}$ & $\begin{array}{c}\text { Ash } \\
(\mathrm{g} / 100 \mathrm{~g})\end{array}$ & $\begin{array}{l}\text { Protein } \\
(\mathrm{g} / 100 \mathrm{~g})\end{array}$ & $\begin{array}{c}\text { Fat } \\
(\mathrm{g} / 100 \mathrm{~g})\end{array}$ \\
\hline$P$ & $65.57 \pm 2.61^{\mathrm{a}}$ & $64.38 \pm 1.02^{\mathrm{a}}$ & $0.62 \pm 0.01^{a}$ & $11.63 \pm 0.06^{b}$ & $9.64 \pm 0.05^{b}$ \\
\hline PS & $71.67 \pm 2.51^{\mathrm{a}}$ & $68.20 \pm 1.01^{a}$ & $0.64 \pm 0.01^{\mathrm{a}}$ & $9.22 \pm 0.52^{\mathrm{a}}$ & $8.56 \pm 0.04^{a}$ \\
\hline PSP & $72.09 \pm 2.32^{\mathrm{a}}$ & $67.92 \pm 0.05^{\mathrm{a}}$ & $0.66 \pm 0.01^{\mathrm{a}}$ & $8.73 \pm 0.05^{\mathrm{a}}$ & $8.215 \pm 0.17^{2}$ \\
\hline
\end{tabular}




\section{Conclusion}

The newly developed synbiotic soy cheese in this study might be a suitable carrier of probiotic $L A-1.0738$, in which the viable bacteria remained at the recommended functional level of above $10^{8} \mathrm{CFU} / \mathrm{g}$ after 28 days of storage. Furthermore, the addition of probiotic and GOS:IN combination significantly improved the technological, physicochemical and sensory characteristics of soy cheese compared with the addition of only $L A-1.0738$. Further research is required to clarify the specific mechanisms involved in this synbiotic effect in responding to consumer health, and to confirm the effectiveness of the product in vivo.

\section{References}

Ambalam, P., Kondepudi, K.K., Balusupati, P., Nilsson, I., Wadström, T. and Ljungh, Å., 2015. Prebiotic preferences of human lactobacilli strains in co-culture with bifidobacteria and antimicrobial activity against Clostridium difficile. Journal of Applied Microbiology 119: 1672-1682. https://doi.org/10.1111/jam.12953

Andersen, J.M., Barrangou, R., Hachem, M.A., Lahtinen, S., Yong, J.G., Svensson, B. and Klaenhammer, T.R., 2011. Transcriptional and functional analysis of galactooligosaccharide uptake by lacS in Lactobacillus acidophilus. Proceedings of the National Academy of Sciences of the United States of America 108: 17785-17790. https://doi.org/10.1073/pnas.1114152108

Ann, E.Y., Kim, Y., Oh, S., Imm, J.Y. and Kim, S.H., 2007. Microencapsulation of Lactobacillus acidophilus ATCC 43121 with prebiotic substrates using a hybridisation system. International Journal of Food Science \& Technology 42: 411-419. https://doi.org/10.1111/j.1365-2621.2007.01236.x

Association of Official Analytical Chemists (AOAC), 2000. Official methods of analysis. AOAC, Arlington, VA, USA.

Barbosa, I.C., Oliveira, M.E., Madruga, M.S., Gullon, B., Pacheco, M.T., Gomes, A.M., Batista, A.S., Pintado, M.M., Souza, E.L. and Queiroga, R.C., 2016. Influence of the addition of Lactobacillus acidophilus La-05, Bifidobacterium animal is subsp. lactis Bb-12 and inulin on the technological, physicochemical, microbiological and sensory features of creamy goat cheese. Food Function 7: 4356-4371. https://doi.org/10.1039/c6fo00657d

Bedani, R., Campos, M.M.S., Castro, I.A., Rossi, E.A. and Saad, S.M.I., 2013. Incorporation of soybean by-product okara and inulin in a probiotic soy yoghurt: texture profile and sensory acceptance. Journal of the Science of Food and Agriculture 94: 119-125. https://doi.org/10.1002/jsfa.6212

Bergamini, C.V., Hynes, E.R., Palma, S.B., Sabbag, N.G. and Zalazar, C.A., 2009. Proteolytic activity of three probiotic strains in semi-hard cheese as single and mixed cultures: Lactobacillus acidophilus, Lactobacillus paracasei and Bifidobacteriumlactis. International Dairy Journal 19: 467-475. https://doi.org/10.1016/j. idairyj.2009.02.008

Cardarelli, H.R., Buriti, F.C.A., Castro, I.A. and Saad, S.M.I., 2007. Inulin and oligofructose improve sensory quality and increase the probiotic viable count in potentially synbiotic petit-suisse cheese.
LWT - Food Science and Technology 41: 1037-1046. https://doi. org/10.1016/j.lwt.2007.07.001

Cassani, L., Gomez-Zavaglia, A. and Simal-Gandara, J., 2020. Technological strategies ensuring the safe arrival of beneficial microorganisms to the gut: from food processing and storage to their passage through the gastrointestinal tract. Food Research International 129: 1-80. https://doi.org/10.1016/j.foodres.2019.108852

Chaturika, J.R.K. and Hyun-Dong, P., 2018. Modifications of nutritional, structural, and sensory characteristics of non-dairy soy cheese analogs to improve their quality attributes. Journal of Food Science and Technology 55: 4384-4394. https://doi.org/10.1007/ s13197-018-3408-3

Chen, K.I., Erh, M.H., Su, N.W., Liu, W.H., Chou, C.C. and Cheng, K.C., 2012. Soyfoods and soybean products: from traditional use to modern applications. Applied Microbiology and Biotechnology 96: 9-22. https://doi.org/10.1007/s00253-012-4330-7

Endo, H., Tamura, K., Fukasawa, T., Kanegae, M. and Koga, J., 2012. Comparison of fructooligosaccharide utilization by lactobacillus and bacteroides species. Bioscience Biotechnology \& Biochemistry 76: 176-179. https://doi.org/10.1271/bbb.110496

Feeney, E.P., Fox, P.F. and Guinee, T.P., 2001. Effect of ripening temperature on the quality of low moisture Mozzarella cheese: 1 . Composition and proteolysis. Dairy Science and Technology 81: 463-474. https://doi.org/10.1051/lait:2001145

Gomes, A.A., Braga, S.P., Cruz, A.G., Cadena, R.S., Lollo, P.C.B., Carvalho,C., Amaya-Farfán, J., Faria, J.A.F. and Bolini, H.M.A., 2011. Effect of the inoculation level of Lactobacillus acidophilus in probiotic cheese on the physicochemical features and sensory performance compared with commercial cheeses. Journal of Dairy Science 94: 4777-4786. https://doi.org/10.1002/jsfa.6212

Hana, K., Martin, S., Ludmila, T., Dagmar, S., Elzbieta, C., Ilona, R., Tomas, H., Irma, S., Petra, H., Zuzana, Z., Tamara, A.-P., Anna, K.-B., Helena, T.-H. andBozena, C., 2016. Colonization of germfree mice with a mixture of three lactobacillus strains enhances the integrity of gut mucosa and ameliorates allergic sensitization. Cellular \& Molecular Immunology 13: 251-262. https://doi. org/10.1038/cmi.2015.09

Hough, G., 2010. Sensory shelf life estimation of food products. CRC Press, Boca Raton, FL, USA, 239 pp. https://doi. org/10.1201/9781420092943

Kumar, G.S., Kumar, T.M. and Nachiket, K., 2018. Effect of composition and storage time on some physico-chemical and rheological properties of probiotic soy-cheese spread. Journal of Food Science and Technology 55: 1667-1674. https://doi.org/10.1007/ s13197-018-3078-1

Langa, S., Bulck, E.v.d., Peirotén, A., Gaya, P., Schols, H.A. and Arqués, J.L., 2019. Application of lactobacilli and prebiotic oligosaccharides for the development of a synbiotic semi-hard cheese. LWT - Food Science and Technology 114: 1-6. https://doi. org/10.1016/j.lwt.2019.108361

Le, B., Ngoc, A.P.T. and Yang, S.H., 2019. Synbiotic fermented soymilk with Weissellacibaria FB069 and xylooligosaccharides prevents proliferation in human colon cancer cells. Journal of Applied Microbiology 128: 1486-1496. https://doi.org/10.1111/jam.14551 Li, A.L., Sun, Y.Q., Du, P., Meng, X.C., Guo, L., Li, S. and Zhang, C., 2017a. The effect of Lactobacillus actobacillus peptidoglycan on 
bovine $\beta$-lactoglobulin-sensitized mice via TLR2/NF- $\mathrm{kBpathway.}$ Iranian Journal of Allergy Asthma \& Immunology 16: 147.

Li, C., Rui, X., Zhang, Y., Cai, F., Chen, X. and Jiang, M., 2017b. Production of tofu by lactic acid bacteria isolated from naturally fermented soy whey and evaluation of its quality. LWT - Food Science and Technology 82: 227-234. https://doi.org/10.1016/j. lwt.2017.04.054

Li, S., Tang, S., He, Q., Gong, J. and Hu, J., 2019. Physicochemical, textural and volatile characteristics of fermented milk co-ultured with Streptococcus thermophilus, Bifidobacteriumanimalis or Lactobacillus plantarum. International Journal of Food Science \& Technology 62: 461-474. https://doi.org/10.1111/ijfs.14279

Liong, M.T., Easa, A.M., Lim, P.T. and Kang, J.Y., 2010. Survival, growth characteristics and bioactive potential of Lactobacillus acidophilus in a soy-based cream cheese. Journal of the Science of Food \& Agriculture 89: 1382-1391. https://doi.org/10.1002/ jsfa.3598

Matias, N.S., Bedani, R., Castro, I.A. and Saad, S.M.I., 2014. A probiotic soy-based innovative product as an alternative to petit-suisse cheese. LWT - Food Science and Technology 59: 411-417. https://doi.org/10.1016/j.lwt.2014.05.054

Mishra, S. and Mishra, H.N., 2018. Comparative study of the synbiotic effect of inulin and fructo-oligosaccharide with probiotics with regard to the various properties of fermented soy milk. Food Science and Technology International 24: 564-575. https://doi. org/10.1177/1082013218776529

Ong, L., Henriksson, A. and Shah, N.P., 2005. Development of probiotic Cheddar cheese containing Lactobacillus acidophilus, Lb. casei , Lb. paracasei and Bifidobacterium spp. and the influence of these bacteria on proteolytic patterns and production of organic acid. International Dairy Journal 16: 446-456. https://doi. org/10.1016/j.idairyj.2005.05.008

Plaza-Diaz, J., Gomez-Llorente, C., Fontana, L. and Gil, A., 2014. Modulation of immunity and inflammatory gene expression in the gut, in inflammatory diseases of the gut and in the liver by probiotics. World Journal of Gastroenterology 20: 15632-15649. https://doi.org/10.3748/wjg.v20.i42.15632

Rodrigues, D., Rocha-Santos, T.A.P., Gomes, A.M., Goodfellow, B.J. and Freitas, A.C., 2012. Lipolysis in probiotic and synbiotic cheese: the influence of probiotic bacteria, prebiotic compounds and ripening time on free fatty acid profiles. Food Chemistry 131: 1414-1421. https://doi.org/10.1016/j.foodchem.2011.10.010

Rui, X., Wang, M., Zhang, Y., Chen, X., Li, L., Liu, Y. and Dong, M., 2017. Optimization of soy solid-state fermentation with selected lactic acid bacteria and the effect on the anti-nutritional components. Journal of Food Processing and Preservation 41: 1-7. https://doi.org/10.1111/jfpp.13290

Samadrita, S., Hemanta, K., Shanta, D. and Jayati, B., 2019. Hepatoprotective effects of synbiotic soy yogurt on mice fed a high-cholesterol diet. Nutrition 63: 36-44. https://doi. org/10.1016/j.nut.2019.01.009

Santichai, N., Chatrudee, S. and Kornchanok, W., 2019. Effect of prebiotics-enhanced probiotics on the growth of Streptococcus mutans. International Journal of Microbiology 2019: 1-7. https:// doi.org/10.1155/2019/4623807

Santos, D.C.d., Filho, J.G.d.O., Santana, A.C.A., Freitas, B.S.M.d., Silva, F.G., Takeuchi, K.P. and Egea, M.B., 2019. Optimization of soymilk fermentation with kefir and the addition of inulin: physicochemical, sensory and technological characteristics. LWT - Food Science and Technology 104: 30-37. https://doi. org/10.1016/j.lwt.2019.01.030

Sebnem, O.B., Ceren, A.H., İlkay, B. and Atila, Y., 2019. Effect of inulin polymerization degree on various properties of synbiotic fermented milk, including Lactobacillus acidophilus La-5 and Bifidobacteriumanimalis Bb-12. Journal of Dairy Science 102: 6901-6913. https://doi.org/10.3168/jds.2019-16479

Valle, B.J., Augusto, d.S.J., Rafael, F., Giselle, N.C. and Joice, S.D.S., 2019. Reduced-fat Frescal sheep milk cheese with inulin: a first report about technological aspects and sensory evaluation. The Journal of Dairy Research 86: 368-373. https://doi.org/10.1017/ S0022029919000487

Wang, J.J., Li, S.H., Li, A.L., Zhang, Q.M., Ni, W.W., Li, M.N., Meng, X.C., Li, C., Jiang, S.L., Pan, J.C. and Li, Y.Y., 2018. Effect of Lactobacillus acidophilus KLDS 1.0738 on miRNA expression in in vitro and in vivo models of beta-lactoglobulin allergy. Bioscience, Biotechnology and Biochemistry 82: 1955-1963. https://doi.org/10.1080/09168451.2018.1495551

Welman, A. and Maddox, I.S., 2003. Exopolysaccharides from lactic acid bacteria: perspectives and challenges. Trends in Biotechnology 21: 269-274. https://doi.org/10.1016/S0167-7799(03)00107-0 